\title{
Resíduo Sólido: Uma Análise Gerencial da sua Destinação por Usuários da Região Metropolitana do Cariri
}

\author{
Desirée Santos Sampaio ${ }^{1}$; Ossian Soares Landim²
}

\begin{abstract}
Resumo: Os resíduos sólidos são vistos como verdadeiros problemas quando relacionados à saúde e saneamento básico, se os habitantes não efetuarem o seu manejo corretamente acaba causando danos tanto para a natureza quanto para a população. Com a segmentação correta dos resíduos sólidos pode-se, não somente acabar com os problemas relacionados ao ecossistema como também garantir o bem-estar da população. Este artigo tem como objetivo identificar os principais destinos dos resíduos sólidos. A metodologia empregada foi de pesquisa quantitativa do tipo pesquisa de opinião, pesquisa bibliográfica e a pesquisa qualitativa e a aplicação de questionários onde foram realizadas algumas perguntas objetivas, onde houve a constatação do conhecimento de algumas pessoas a sobre o referido assunto. Foi notado que ainda existe a falta de conhecimento a respeito da sua importância.
\end{abstract}

Palavras-chave: Resíduos Sólidos. Descarte. Seletividade.

\section{Solid Waste: A Management Analysis of its Destination by Users of the Metropolitan Region of Cariri}

\begin{abstract}
Solid waste is seen as a real problem when it comes to health and sanitation, if the inhabitants do not manage it correctly, it ends up causing damage to both nature and the population. With the correct segmentation of solid waste, one can not only end with problems related to the ecosystem, but also guarantee the well-being of the population. This article aims to identify the main destinations of solid waste. The methodology used was quantitative research such as opinion research, bibliographic research and qualitative research, and the application of questionnaires where some objective questions were asked, where the knowledge of some people about this subject was verified. It was noted that there is still a lack of knowledge about its importance.
\end{abstract}

keywords: Solid Wast. Discard. Selectivity.

\section{Introdução}

Segundo Schneider (2004), os resíduos produzidos por estabelecimentos de saúde ainda são um dos principais problemas ambientais ocasionados pela quantidade insignificante de reciclagem e o descarte incorreto. A segmentação correta dos resíduos podem diminuir a poluição e assim minimizar os custos do tratamento.

\footnotetext{
${ }^{1}$ Graduando em Administração do Centro Universitário Doutor Leão Sampaio, Juazeiro do Norte, Ceará, Brasil. E-mail: desyresampaio@ hotmail.com ${ }^{2}$ Mestre do Centro Universitário Doutor Leão Sampaio, Juazeiro do Norte, Ceará. ossian@ leaosampaio.edu.br

211 Id on Line Rev. Mult. Psic. V.12, N. 42, Supl. 1, p. 211-228, 2018 - ISSN 1981-1179 Edição eletrônica em http://idonline.emnuvens.com.br/id
} 
Várias organizações e comunidade ainda não possuem gerenciamento e tratamento correto para os descartes destes itens. Com o desenvolvimento populacional, os avanços científicos, tecnológicos e desenvolvimento industrial, o descarte de resíduos resultou em um problema ainda bem superior.

Os riscos ambientais, ocasionados por manuseamento inapropriado dos resíduos vai muito além do que imaginamos, causando doenças e afetando a qualidade de vida da população que direta ou indiretamente pode chegar a ter contato com o material que foi descartado.

A finalidade inadequada destes resíduos vem ocasionando problemas ambientais, sociais e sanitários. Apenas um apropriado gerenciamento dos resíduos de sólidos será capaz de controlar esses impactos negativos. Portanto o Plano de Gerenciamento de Resíduos de Serviço de Saúde (PGRSS) passou a ser obrigatório nas instituições que produzem alguns resíduos devido ao grave risco ocasionado ao ser humano e ao ecossistema.

Diante do contexto existente desse modo diversas empresas, organizações e sociedade não sabe como realizar o descarte correto dos resíduos, que vem ocasionando vários problemas para o meio ambiente. Nesse caso questiona-se: Quais os principais destinos dos resíduos sólidos.

A pesquisa tem como objetivo identificar quais os principais destinos dos resíduos sólidos, compreender a classificação destes resíduos, analisar como são feita a coleta seletiva.

Os resíduos que forem produzidos em hospitais, clínicas ou laboratórios, podem ser tóxicos, químicos e perfurantes, no caso do hospital tem sua grande maioria o lixo tóxico e químico, por isso o descarte correto é de grande importância tanto para a sociedade quanto para o meio-ambiente.

A ABRELPE (Associação Brasileira de Empresas de Limpeza Pública e Resíduos Especiais) divulgou que no ano de 2013 que somente 44\% dos resíduos gerados pelo setor de saúde tiveram sua entrada na incineração correta, uma porcentagem baixíssima quando comparada aos números de hospitais existentes e a quantidade de lixo produzido, posto que o impacto ambiental pelo lixo descartado de forma incorreta é de considerável monta.

Convém que os órgãos fiscalizadores, tanto a nível Municipal, Estadual e Federal exerçam o seu papel com vistas a fazer cumprir a legislação pertinente, o que viria a trazer benefícios enormes para a população e o Meio-Ambiente. O objetivo da medida é evitar danos 
ao ecossistema e prevenir acidentes que atinjam profissionais que trabalham diretamente nos processos de coleta, armazenamento, transporte, tratamento e destinação desses resíduos.

Os riscos que esses resíduos podem proporcionar a população e ao meio ambiente devemos presumir de responsabilidade dos gestores dos estabelecimentos a destinação devida destes resíduos, apresentando alguns à obrigação de ser realizado todo o processo ainda dentro da unidade geradora.

\section{Referencial Teórico}

\section{Resíduos Sólidos}

A preocupação com o descarte dos resíduos vem causando um grande conflito há algumas décadas nas áreas nacional e internacional, devido o crescimento da população e da consciência coletiva de cada um com relação ao ecossistema. A demanda por soluções na área de resíduos reflete um vasto crescimento da sociedade que comprime por mudanças motivadas pelos custos socioeconômicos e ambientais. Para que aconteça a restrição de resíduos gerados pelas organizações e administrado pelos clientes é significativo que todos esses resíduos sólidos tenham uma finalidade estabelecida de forma correta para que aconteça a redução de impactos ambientais.

Para Silva (2014), com o desenvolvimento populacional, e industrial consequentemente a produção de bens de consumo, a tendência é aumentar o volume de resíduos gerados; em decorrência do homem satisfizer as suas necessidades cotidianas. Com as inovações tecnológicas advindo da revolução industrial, o lixo passou a ter várias definições, exigindo outras considerações a fim de que os municípios planejassem melhores formas de manejo dos resíduos, tornando-os adequado e eficiente.

Segundo Costa (2011), com a geração destes resíduos tornou-se um largo crescimento no mundo com reflexos que exorbita a região ambiental, haja vista que a escassez de sustentabilidade do ciclo linear de produção, consumo e descarte de materiais, além de esgotar as reservas naturais, tem transformado o planeta em um largo depósito de lixo, causando a degradação do meio ambiente e afetando a saúde da população.

213 Id on Line Rev. Mult. Psic. V.12, N. 42, Supl. 1, p. 211-228, 2018 - ISSN 1981-1179 Edição eletrônica em http://idonline.emnuvens.com.br/id 
De acordo com Barsano (2014), dentro do conjunto de situação dos resíduos sólidos, segundo a norma da ABNT NBR 10004 e a política nacional de resíduos (Lei federal no 12.305/2010), a presença de microorganismos patogênicos (que causam doenças) leva o resíduo a ser classificado como perigoso. Para a gerência de resíduos desta classe é solicitados cuidados especiais tendo em vista evitar a contaminação de pessoas e do meio ambiente.

Ainda sobre os resíduos produzidos pelo setor de saúde Barsano (2014), afirma que o mesmo recebe análise especial, em virtude de suas especificidades. Onde a classificação que exerce, para esse tipo de resíduos, bem como os métodos para seu gerenciamento é estabelecida pela RDC ANVISA no 306/104 e resolução CONAMA n 358/05.

\section{Classificação}

Segundo Philippi Jr (2004), os resíduos nos estados sólidos e semissólido, que transformam em atividades das comunidades de origem são: Industrial, Doméstica, Hospitalar, Comercial, Agrícola, de Serviço e de Varrição. Conceituam também resíduos sólidos os lodos procedentes de sistemas de tratamento de água aqueles gerados em equipamentos e instalações.

De acordo com a NBR 10004 até então classifica os resíduos quanto aos riscos potenciais ao meio ambiente e à saúde pública. Eles podem ser de Classe I - Perigosos ou Classe II - Não Perigosos.

Segundo Araújo, os Resíduos Classe I - Perigosos são aqueles cuja propriedade física, químicas ou infecto-contagiosas que podem provocar graves riscos à saúde pública, como também riscos ao meio ambiente, quando os resíduos estiverem sendo descartado de forma inadequada.

Sendo assim os resíduos da Classe I deve estar contido nos seguintes anexos A ou B da NBR 10004 ou apresentar uma ou mais das seguintes características: Inflamabilidade, Corrosividade, Reatividade, Toxicidade e Patogenicidade.

Classe II A ou Resíduos não inertes, a NBR 10004, (2004), classifica como: Aqueles que não se encaixam nas classificações de resíduos classe I - perigosos ou de classe II B inertes, nos termos desta norma. Os resíduos classe II A podem ter propriedades, tais como: biodegradabilidade, combustibilidade e solubilidade em água. 
Classe II B ou Resíduos inertes, a NBR 10004, (2004), Classifica como: Quaisquer resíduos que, quando amostrados de uma forma representativa, segundo ABNT - NBR 10007, e submetidos a um contato com água destilada e deionizada, à temperatura ambiente, conforme ABNT - NBR 10006, não tiverem nenhum de seus constituintes solubilizados a concentrações superiores aos padrões de portabilidade de água, excetuando-se aspectos, cor, turbines, dureza e sabor, conforme anexo G desta NBR.

\section{Tipos de resíduos sólidos}

A classificação dos resíduos sólidos vem tendo um processo de crescimento contínuo, na medida em que vão incluindo novos tipos de resíduos nas unidades e como resultado do conhecimento da conduta destes perante o meio ambiente e à população, como forma de determinar uma gestão com base nos princípios da avaliação e gerenciamento dos riscos envolvidos na sua seleção.

Segundo Faria (2008), existem cinco tipos de resíduos sólidos que precisamos entender cada um deles:

1. Resíduos Sólidos Urbanos: São gerados nas cidades e coletados pelo serviço municipal (residência, comércios, varrição e, em alguns casos, entulhos). Normalmente são constituídos por resíduos de natureza orgânica, recicláveis em geral como: papel, plástico, vidro e inorgânico que são produtos manufaturados em geral incluindo poucos recicláveis como metais, espumas e isopor.

2. Resíduos Industriais: São resultante dos sistemas produtivos das industrias (usinagem, fabricação e montagens de peças, fabricação de alimentos entre outros) podendo englobar no estado sólido, semissólido, líquido ou gasoso. Segundo a Norma Técnica, NBR 10.004/2004 esse tipo de resíduos se classifica como I ou II.

3. Resíduos Hospitalares: São os resíduos gerados em unidade hospitalar, clínicas médicas e odontológicas, laboratórios de análises clínicas, farmácias, entre outras. Segundo a RDC ANVISA n 306/04 e Resolução CONAMA n 308/5, os Resíduos Sólidos de Saúde (RSS), são Classificados em cinco grupos: A, B, C, D e E.

Grupo A - Resíduos Infectantes, Grupo B - Resíduos de Origem Química, Grupo C Resíduos Radioativos, Grupo D - Resíduos Comuns, Grupo E - Resíduos Perfurocortantes. 
Independente do grupo dos resíduos e de responsabilidade da unidade ou empresa realizar o descarte correto.

4. Resíduos de Construção Civil: Esses resíduos são resultante de obras civis, tendo como exemplo: construções, demolições, reformas, ampliações e vários outros geralmente conhecido como entulho.

5. Resíduos Nucleares: De acordo com a resolução CNEN - 6.05, se enquadra no grupo das substancias radioativos ou contaminados com radionuclídeos que são provenientes de laboratórios de análises clínicas, serviços de medicina nuclear e radioterapia. Todo setor produtor usuário desses resíduos nucleares devem obedecer às normas do CNEN - Comissão Nacional de Energia Nuclear, que determina todas as regras a serem adotadas desde a geração do produto até a destinação final do resíduo.

\section{Coleta Seletiva e Logística Reversa}

Segundo o site Ministério Do Meio Ambiente, fala que a coleta seletiva é feita por uma separação de resíduos de acordo com a sua constituição e composição. Ou seja, resíduos com atributos idênticos são separados pelo causador sendo ele cidadão, entidade ou organização, e proporcionando a recolhida separadamente.

De acordo com o site do Ministério Do Meio Ambiente, cita que de acordo com a Política Nacional de Resíduos Sólidos, a implantação da coleta seletiva é obrigatoriedade dos munícipios e objetivos relacionados à coleta seletiva incluem-se na temática mínima que deve ter nos planos de gestão integrada de resíduos sólidos dos munícipios.

Segundo o site da Verde Ghaia (2018), a coleta seletiva contém uma correta segregação dos resíduos adequada de acordo com cada composição. Essa atitude é muito importante para o gerenciamento de resíduos Sólidos.

As formas mais utilizadas para a coleta seletiva nas cidades são a coleta porta-a-aporta e a coleta por pontos de entrega voluntária que são iniciativas de algumas empresas ou organizações. A coleta porta-a-porta é feita por colaboradores do serviço público de limpeza, esses resíduos geralmente são jogados em terrenos baldios a céu aberto sendo lá feita a separação por alguns prestadores de serviço para que haja a venda, chegando a gerar uma renda extra para os mesmos. 
Desta forma não havendo essa separação dos resíduos acaba aumentando a poluição no meio ambiente e acarretando cada vez mais no tempo de nossas vidas, porque temos contato com ambientes poluídos.

Segundo o site Ministério Do Meio Ambiente, a logística reversa é de reponsabilidade dos produtores, importadores, distribuidores e comerciantes de determinadas classes de produtos como: pneus, pilhas, baterias, e lâmpadas fluorescentes, para que sejam reinseridos no ciclo produtivo ou ser dada a destinação correta destes resíduos.

A logística da coleta nas cidades é feita por meio de um caminhão ou outro veículo que passa em frente às residências, comércios e organização fazendo a coleta desses resíduos que muitas vezes são feitas as separações pela comunidade.

\section{Incineração}

Para Furtado (2017), o intuito de amenizar e extinguir os resíduos, através da queima do lixo em elevadas temperaturas esse é o principal objetivo da incineração, seu processo monitorado se dar por meio dos incineradores, cujos resíduos são queimados em temperaturas acima de $900^{\circ} \mathrm{C}$, deixando apenas as cinzas como produtos inertes. Tem sua maior serventia para a ação da eliminação dos materiais perigosos, sendo o alvo ideal em hospitais, laboratórios e farmácias. Uma das grandes desvantagens é o custo elevado da incineração, que se dá por conta das poucas empresas incineradoras existentes.

Para Valle (2012) a incineração de resíduos é uma maneira que desfruta da energia térmica, com o objetivo de exterminar os resíduos, transformando-os em cinzas, e diminuir inteiramente a quantidade de resíduos, como também pode ser uma geradora de energia, no caso se for utilizada para incinerar resíduos combustíveis.

Philippi et al (2004) afirma que a incineração é uma técnica utilizada para a eliminação dos resíduos, execução existente a mais de cem anos, são os mesmos relacionados a instalações que emitem firme odor e possui uma fumaça preta, visando à redução do volume dos resíduos, tendo como objetivo a extinção de resíduos tóxicos ou perigosos. 


\section{Metodologia}

O presente trabalho adotou a pesquisa quantitativa, que para Frankenthal (2016), essa pesquisa é concludente, e tem como finalidade estimar uma situação e entender o dimensionamento dela. Esse tipo de pesquisa tem por finalidade o fornecimento de informações numéricas sobre o tema abordado.

Utilizam-se questionários estruturados com a maioria das perguntas fechadas, que os participantes têm como opções uma listagem de resposta para assinalar o feedback que achar coerente. Sendo utilizada também a pesquisa de opinião que de acordo com site Institutophd, a pesquisa de opinião também chamada como sondagem é um levantamento estatístico de dados específicos do ponto de vista público. Ela estabelece as concepções de uma determinada população analisada, por meio de perguntas para que haja uma fatia do referido grupo e análise.

Utilizando-se também para isso como base a pesquisa bibliográfica como que foi selecionada levando em importância o valor que conseguiria acrescentar aos conhecimentos já adquiridos no que diz respeito aos aspectos ambientais. Para Alves (2007), a pesquisa bibliográfica é produzida com base em fatores já desenvolvidos, como livros, artigos científicos, publicações entre outros. Segundo o site Significado, a pesquisa qualitativa é um critério de averiguação cientifica que se enfatizando no tipo de subjetivo do objeto de analise, pesquisando as suas originalidades e conhecimento individuais.

A metodologia utilizada durante o estudo foi de abordagem de pesquisa quantitativa do tipo pesquisa de opinião, onde houve a aplicação de 198 questionários contendo o total de dez questões sendo objetivas. Os referidos formulários foi adequado no aplicativo google forms e foram publicados em grupos de whatsApp, messenger e instagram, chegando a obter essa abrangência na região metropolitana do cariri e quantidade alcançada. Utilizou-se também da pesquisa bibliográfica e a pesquisa qualitativa, para o melhor entendimento dos descartes de resíduos sólidos onde através do referencial teórico pode-se obter um melhor entendimento em relação ao proposto projeto de pesquisa de opinião.

218 Id on Line Rev. Mult. Psic. V.12, N. 42, Supl. 1, p. 211-228, 2018 - ISSN 1981-1179 Edição eletrônica em http://idonline.emnuvens.com.br/id 


\section{Análise e Discussão dos Resultados}

Em vista a realização da pesquisa de opinião executada através da aplicação de 198 (cento e noventa e oito) questionários, teve como objetivo o levantamento das informações e a obtenção dos seguintes dados.

Gráfico 01: Resíduos Sólidos

\section{Você sabe o que é resíduo sólido?}

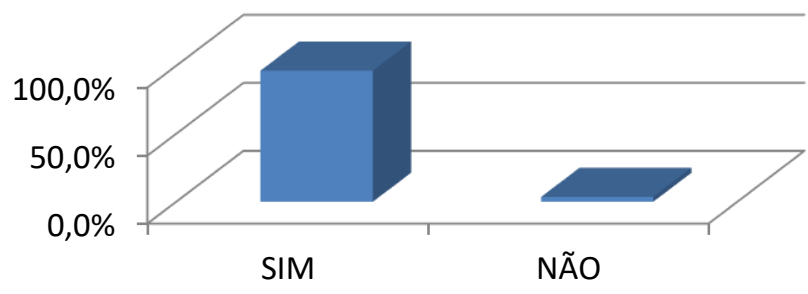

Fonte: Dados da Pesquisa 2018.

De acordo com a análise do gráfico $01,96,4 \%$ das pessoas que responderam o questionário sabe o que é resíduo sólido, já 3,6\% não sabe. Com esse resultado nota-se que ainda existe a falta de conhecimento sobre esse tema tão importante para toda a sociedade.

Para continuar com esse número bem estimado de pessoas que sabem o que significa o que é resíduo sólido ou até melhorá-los cada vez mais, é de suma relevância cada cidade realizar campanhas explicando a sua importância ao realizar o passa a passo de forma correta explicando o que trará de benefícios ao realizar o descarte correto.

Gráfico 02: Classificação dos Resíduos Sólidos.

\section{Você sabe classificar os resíduos sólidos?}

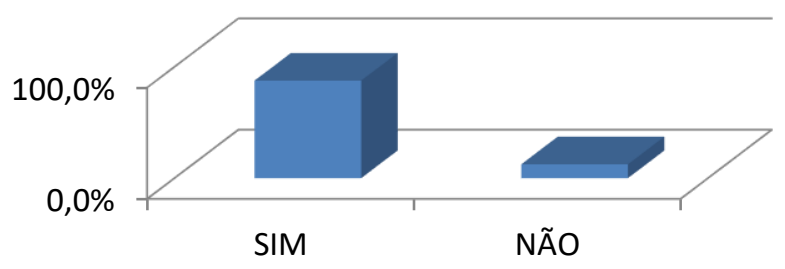

Fonte: Dados da Pesquisa 2018. 
Na classificação dos resíduos 87,6\% respondeu que sabem classificar e 12,4\% não sabe. É de grande importância saber todo o processo de identificação ou atividade que dar a sua originalidade e também a sua composição que cujo causa impacto à saúde e meio ambiente.

Segundo a NBR 10004 faz a classificação destes resíduos de acordo com a intensidade dos riscos ocasionados por eles ao ecossistema e à saúde. Que podem ser da Classe I - que são os perigosos e Classe II - são os não perigosos.

Saber a classificação deste resíduo é de suma importância, eles englobam o reconhecimento do processo ou atividade que deu geração a sua origem, além de existir diversas composições de resíduos e substancia que causam danos a saúde e ao meio ambiente. Existindo o conhecimento sobre cada classificação a o entendimento de como realizar toda a coleta seletiva que cada resíduo se enquadra, sendo elas classes distintas.

O incentivo da cultura da coleta seletiva é muito importante, do pondo de vista observamos que sendo realizada há economia de recursos naturais, energia e água. Havendo os retornos destes materiais recicláveis para a indústria existe a redução de matéria prima retirada do planeta chegando a obter o aumento da vida útil dos aterros sanitários ou centrais de tratamento. Existe também a geração de emprego e renda para as famílias que trabalham na coleta e catação destes objetos, nas cidades e lixões.

Gráfico 03: Serviço de Coleta de Resíduos Sólidos.

\section{Existe serviço de coleta de resíduos sólidos (LIXO) no seu município?}

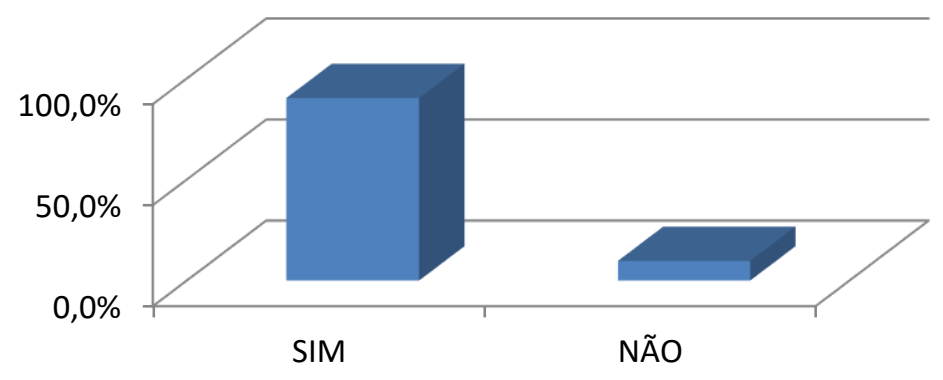

Fonte: Dados da Pesquisa 2018.

Segundo a análise dos dados do gráfico 03, 90,3\% das pessoas respondeu que sim, e já 9,7\% responderam não. Na averiguação deste gráfico nota-se que a maior quantidade dos 
respondentes respondeu que existe a coleta de lixo na sua cidade. Isso significa que a possibilidade do lixo ser descartados em terrenos baldios e queimados é muito pouco. Sendo realizado dessa maneira o descarte não há danificação ao solo por uma parte da população.

Gráfico 04: Frequência da Coleta de Lixo na Cidade.

\section{Qual a frequência da coleta do lixo na sua cidade?}

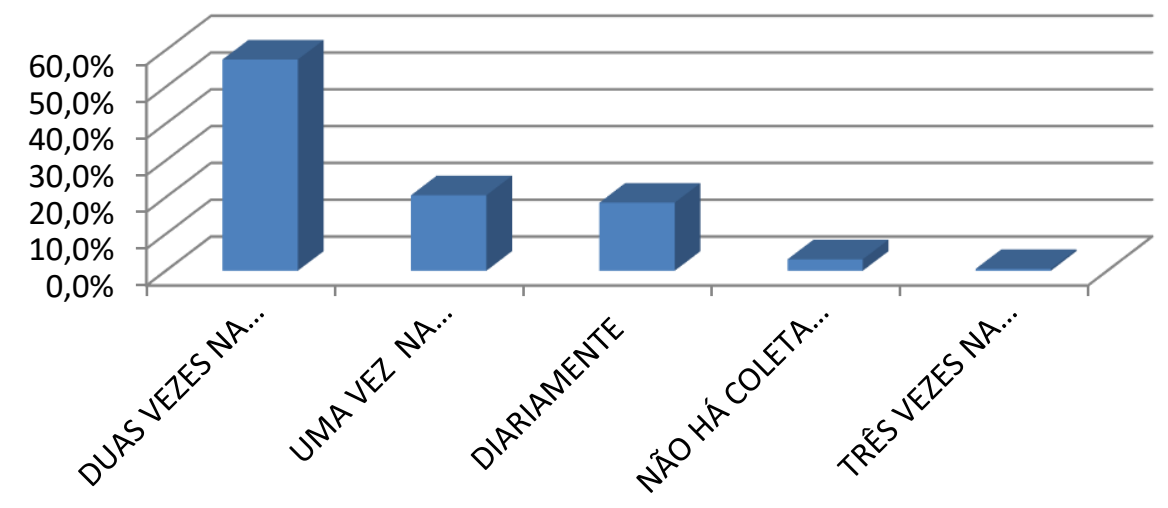

Fonte: Dados da Pesquisa 2018.

No gráfico 04 analise-se que 57,4\% dos participantes confirmaram que a frequência da coleta do lixo na sua cidade é realizada duas vezes por semana, já 20,5\% respondeu que é feita uma vez na semana, $18,5 \%$ diariamente, $0,5 \%$ três vezes por semana, 3,1\% não há coleta direta de lixo.

Segundo o Manual Gerenciamento Integrado de Resíduos Sólidos, a coleta de lixo deve ser feita entre o decorrer da produção e o seu destino final não devendo ultrapassar de uma semana, evitando proliferação de moscas ocasionada através das razões climáticas, odor e insetos, e outros animais. 
Gráfico 05: Coleta Seletiva.

\section{Você sabe o que é coleta seletiva?}

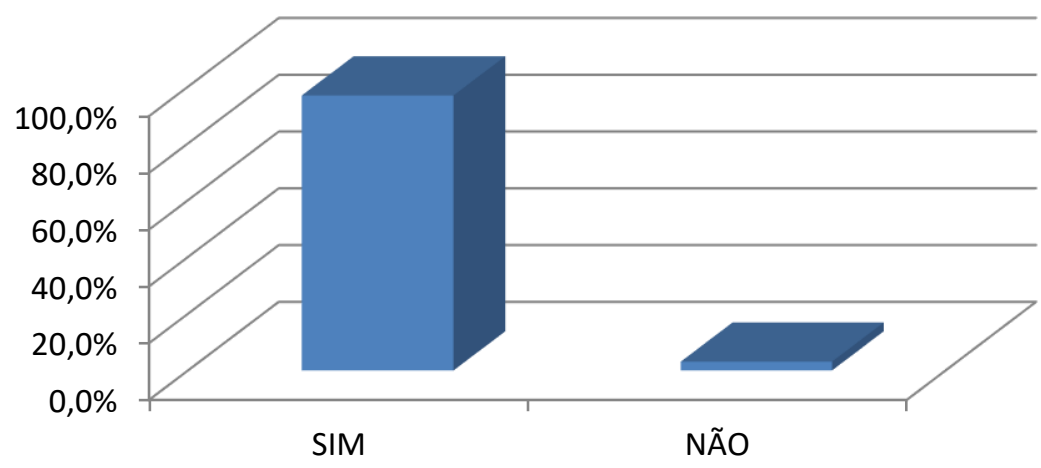

Fonte: Dados da Pesquisa 2018

Conforme a realização da análise de resultado (gráfico 05) 96,9\% sabe o que é coleta seletiva, $3,1 \%$ não sabe. A realização da coleta seletiva é muito importante para a sociedade, além do mais gera renda familiar para várias pessoas e economia para empresas, da mesma forma trás benefícios para o meio ambiente. Sendo assim, ha reutilização de grande quantidade de resíduos que anteriormente era feito o descarte incorreto e com o passar do tempo com o não reaproveitamento aumentaria quantidade de lixos causando impacto global.

Gráfico 06: Destino do Lixo Produzido.

\section{O que você faz com o lixo que você produz?}

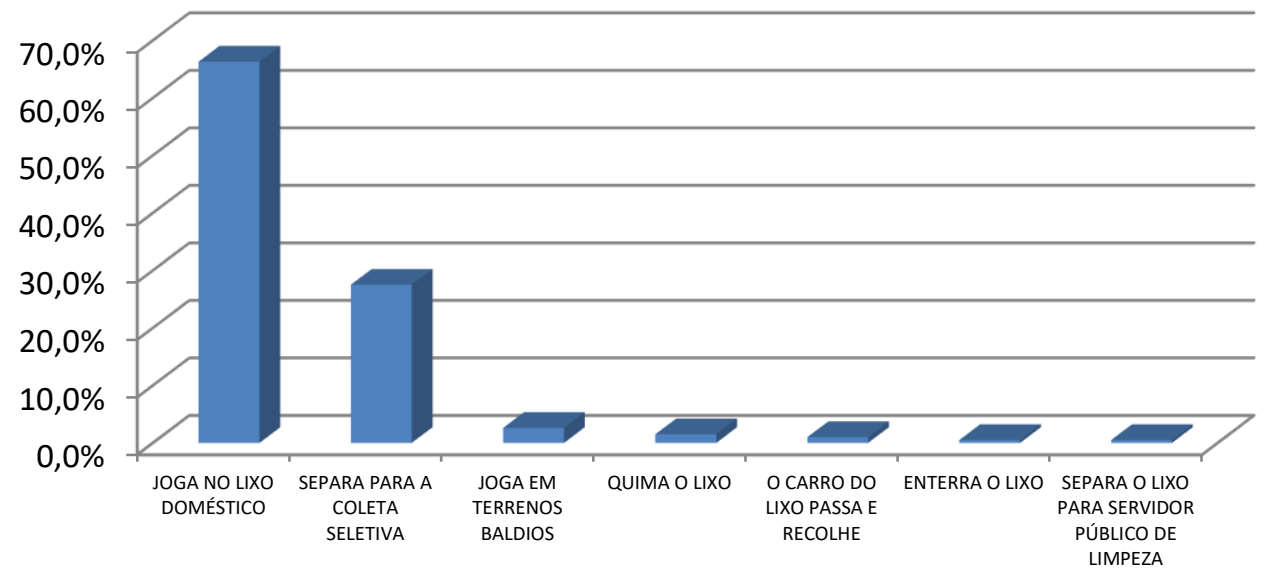

Fonte: Dados da Pesquisa 2018. 
No gráfico 06 nota-se que 66,3\% das pessoas responderam que jogam os resíduos produzidos no lixo doméstico, já 27,5\% falou que separa para a coleta seletiva, 2,6\% joga em terrenos baldios, $1,5 \%$ queima o lixo, $0,5 \%$ enterra o lixo, $0,5 \%$ respondeu que faz a seleção do lixo para os servidores públicos de limpeza coletar $1 \%$ o carro do lixo passa e recolhe.

Ao averiguar esse gráfico nota-se que várias pessoas ainda não fazem o manejo correto do lixo. Quando não há a separação destes lixos para o recolhimento acaba que gerando mais trabalhos para os garis e acarretando vários acidentes. A queima de lixo é prejudicial ao solo, ambiente e sociedade.

Gráfico 07: Separação do Lixo em Casa.

\section{Você faz a separação do lixo da sua casa?}

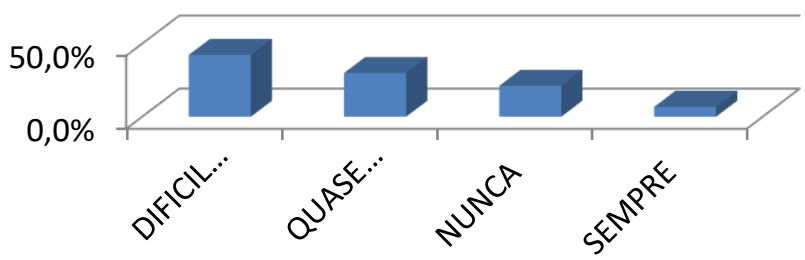

Fonte: Dados da Pesquisa 2018.

Na separação do lixo de casa 42,3\% assinalou a opção que dificilmente faz já, 29,9\% respondeu que realiza quase sempre, $21,1 \%$ nuca realizou e $6,7 \%$ sempre realizam.

Ao realizar a análise deste gráfico e do anterior percebe-se que a falta de conhecimento sobre o referido assunto é muito grande, necessita mais de palestras e incentivo a essa educação. Esses resíduos sendo separados e reciclados de forma correta reduz o impacto sobre o ecossistema, diminui também as retiradas de matéria-prima da natureza. 
Gráfico 08: Compra de Produtos que não Afetem o Meio Ambiente.

\section{Quando você vai fazer compras, se preocupa em escolher produtos que agridem menos 0 meio ambiente?}

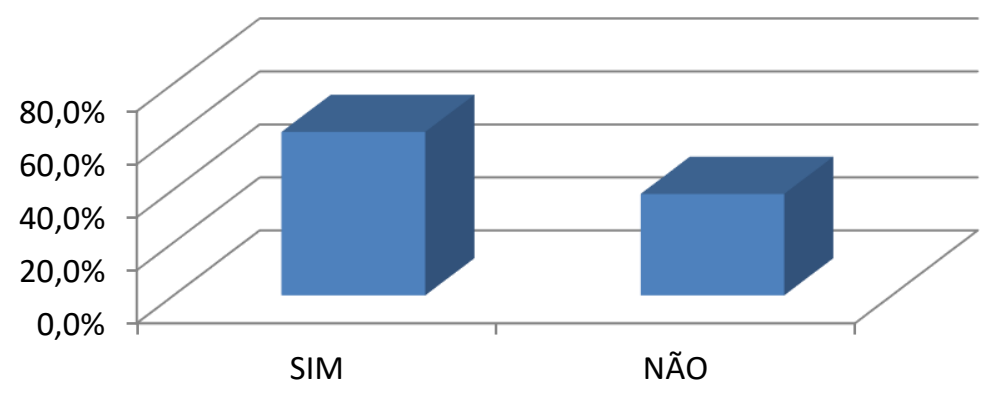

Fonte: Dados da Pesquisa 2018

De acordo com a apuração dos dados $61,7 \%$ dos participantes assinalou a opção que sim, que ao realizar as suas compras se preocupam em escolher produtos que agridem menos o meio ambiente, já 38,3\% optou pela resposta não. Percebe-se que existem muitas pessoas que ainda não são conscientes o quanto pode estar causando danos à natureza com essa atitude da não preocupação ou não conhecimento. Tendo em vista, por exemplo: com os avanços tecnológicos as pessoas trocam de celular constantemente, muitas vezes não pelo fato da necessidade mais por causa do desejo que tem de possuir outro aparelho do novo lançamento.

Gráfico 09: Aterro Sanitário Deve Receber Todo Lixo.

\section{Em sua opinião, o aterro sanitário deve receber todo o lixo?}

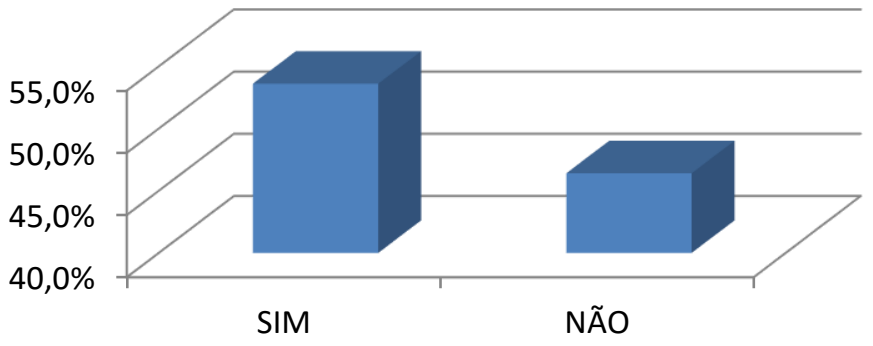

Fonte: Dados da Pesquisa 2018. 
$\mathrm{Na}$ análise de resultados (gráfico 09) 53,6\% optou por sim, que o aterro sanitário deve receber todos os lixos e 46,4\% respondeu que não. Segundo o site Dinâmica Ambiental (2017), os aterros sanitários funcionam sob normas que tem como visão diminuir os danos provocados ao ecossistema e a população que habitam aos redores. Esses aterros deveriam ser constituídos apenas por resíduos não recicláveis, mas a coleta seletiva até o momento não é realizada por uma grande parte da população.

Tendo em visto em gráfico anterior que ainda não existe muito consentimento da realização da coleta seletiva dos lixos gerados. Sendo assim com o descarte incorreto dos resíduos podem acarretar na contaminação do meio ambiente.

Gráfico 10: Reciclar, Reutilizar e Reaproveitar.

\section{Você sabe o significado de reciclar, reutilizar e reaproveitar?}

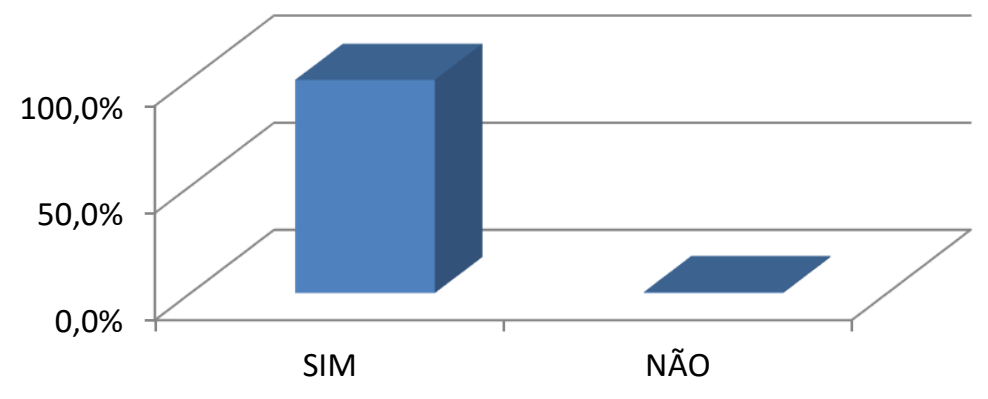

Fonte: Dados da Pesquisa 2018.

Ao observar o resultado do gráfico 10, 99,5\% das pessoas que teve acesso para responder sabe o significado de reciclar, reutilizar e reaproveitar, já a quantidade dos participantes que não sabe é muito pouca $0,5 \%$.

Segundo Castillioni (2016), os 3 Rs da sustentabilidade são atividades voltada para a prática que tem como visam diminuir o desperdício de materiais e produtos, além disso reduzir da natureza a extração inesgotável de recursos. Fazendo dessa forma há a possibilidade de minimizar o custo de vida diminuindo os gastos e também beneficiar o desenvolvimento sustentável. 
Percebe-se que há um grande conhecimento sobre o referido assunto. Se todos souberem fazer a utilização desses 3 Rs da sustentabilidade já é uma grande satisfação para a natureza da não poluição.

\section{Considerações Finais}

Com a finalidade de um gerenciamento dos resíduos sólidos correto, é essencial controlar e diminuir os riscos, devendo reduzir os resíduos gerados, a partir do ponto de origem, o que elevaria a qualidade e a capacidade dos serviços que dispõe pelos estabelecimentos. Um sistema apropriado de manejo dos resíduos sólidos que permite controlar e reduzir, com segurança e economia, os riscos para a saúde e meio ambiente.

Por isso, deve realizar-se toda uma preparação para o processo de administração, e destinação destes resíduos, a partir da fase de identificação dos resíduos até o seguimento de tratamento de disposição final.

Ao analisar os gráficos nota-se que em algumas respostas existe a falta de conhecimento sobre o referido assunto, para que haja o conhecimento sobre esse tema é de extrema necessidade o incentivo e esclarecimento executado por grupos ou equipe de cada cidade.

$\mathrm{O}$ presente estudo se propôs identificar os principais destinos dos resíduos. A metodologia adotada foi à pesquisa quantitativa, utilizando-se também para isso da pesquisa bibliográfica e sites de pesquisas acadêmicas sobre como são feitos esses descartes. Neste estudo foram averiguados os processos adotados na geração, classificação, coleta seletiva, transporte, destinação, disposição final destes resíduos.

\section{Referências}

ALVES, M. Como escrever teses e monografia: um roteiro passo a passo. Rio de Janeiro: Elsevier, 2007.

ARAÚJO, Giovanni Moraes. Normas Regulamentadoras Comentadas e Ilustradas: Legislação de Segurança e Saúde no Trabalho. $8^{\mathbf{a}}$ ed. Rev. Ampliada, Atualizada e Ilustrada. Vol. 3 (NR 17 à NR 34). 
BARSANO, Paulo Roberto; BARBOSA, Rildo Pereira, VIANA, Viviane Japiassú. Poluição ambiental e saúde pública. $1^{\text {a }}$ ed. São Paulo: Érica, 2014.

CASTILLIONI, Karen P. Reduzir, Reutilizar e Reciclar - 3 Rs da Sustentabilidade 2016.

Disponível em: <http://sustentahabilidade.com/reduzir-reutilizar-e-reciclar-3-rs-dasustentabilidade/>. Acesso em: 02 nov. 2018.

COSTA, Sandro Luiz. Gestão Integrada de Resíduos Sólidos Urbanos: Aspectos jurídico e ambientais. $1^{\text {a }}$ ed. Aracaju: Evocati, 2011.

DINÂMICA AMBIENTAL. Saiba Quais São os Principais Tipos de Descarte de Lixo Praticados no Brasil. 2017.2 Disponível <https://www.dinamicambiental.com.br/blog/meio-ambiente/saiba-sao-principais-tiposdescarte-lixo-praticados-brasil/>. Acesso em: 02 nov. 2018.

FARIA, Caroline. Classificação e Tipos de Resíduos Sólidos 2008. Disponível em: <https://www.infoescola.com/ecologia/residuos-solidos/>. Acesso em: 24 out. 2018.

FURTADO, Antônio Sávio Aires. Cartilha - Plano de Gerenciamento de Resíduos de Serviço de Saúde - PGRSS. 2017.

FRANKENTHAL, Rafaela. Pesquisa Quantitativa e Qualitativa: Qual é a Melhor Opção? 2016. Disponível em: < https://mindminers.com/pesquisas/pesquisa-qualitativa-quantitativa>. Acesso em: 03 nov. 2018.

INSTITUTOPHD DIFERENCIAL EM PESQUISA. Pesquisa de Opinião: O que é? Como funciona? 2015. Disponível em: <https://www.institutophd.com.br/pesquisa-de-opiniao-o-quee-como-funciona/>. Acesso em: 03 nov. 2018.

MANUAL GERENCIAMENTO INTEGRADO DE RESÍDUOS SÓLIDOS. Coleta e Transporte de Resíduos Sólidos Domiciliares. Disponível em: < http://www.resol.com.br/cartilha4/coleta/coleta_1.php>. Acesso em: 29 out. 2018.

MINISTÉRIO DO MEIO AMBIENTE. Coleta Seletiva. Disponível em: <http://www.mma.gov.br/cidades-sustentaveis/residuos-solidos/catadores-de-materiaisreciclaveis/reciclagem-e-reaproveitamento.html>. Acesso em: 22 de Out. 2018.

PHILIPPI JR, Arlindo; ROMÉRO, Marcelo de Andrade; BRUNA, Gilda Collet. Curso de Gestão Ambiental: Coleção Ambiental. 1º ed. Barueri, SP: Manole, 2004.

SCHNEIDER, V. E. et al. Manual de gerenciamento de resíduos sólidos de serviços de saúde. 2 ed. Caxias do Sul: Educs, 2004.

SILVA, Claudionor de Oliveira. Resíduos Sólidos: Uma Problemática do Nosso Dia. União dos Palmares: 2014. 
SIGNIFICADOS. Significado de Pesquisa Qualitativa. Disponível em: <https://www.significados.com.br/pesquisa-qualitativa/>. Acesso em: 03 nov. 2018.

TÉCNICO EM RADIOLÓGIA. CNEN-NE- 6.05. Disponível em: $<$ http://rle.dainf.ct.utfpr.edu.br/hipermidia/index.php/protecao-

radiologica/legislacao/recomendacoes-da-cnen/cnen-ne-6-05>. Acesso em: 22 out. 2018.

VALLE, Cyro Eyer. Qualidade ambiental; ISO 14000. 12a Ed. São Paulo: Editora Senac São Paulo, 2012.

VERDE GHAIA. Conceito e Noções Sobre Coleta Seletiva 2018. Disponível em: $<$ https://www.verdeghaia.com.br/blog/conceitos-e-nocoes-sobre-coleta-seletiva/ > . Acesso em: 22 out. 2018.

\section{Como citar este artigo (Formato ABNT):}

SAMPAIO, Desirée Santos;LANDIM, Ossian Soares. Resíduo Sólido: Uma Análise Gerencial da sua Destinação por Usuários da Região Metropolitana do Cariri . Id on Line Rev.Mult. Psic., 2018, vol.12, n.42, Supl. 1, p. 211-228. ISSN: 1981-1179.

Recebido: 02/11/2018;

Aceito: 05/11/2018 